\title{
Herbivore exclusion promotes a more stochastic plant community assembly in a natural grassland
}

\author{
Juan Alberti, ${ }^{1,6}$ Elisabeth S. Bakker, ${ }^{2}$ Roel van Klink, $, 3,5$ Han OlfF, ${ }^{4}$ and Christian Smit ${ }^{4}$ \\ ${ }^{1}$ Laboratorio de Ecología, Instituto de Investigaciones Marinas y Costeras (IIMyC), Universidad Nacional de Mar del Plata, \\ Consejo Nacional de Investigaciones Cientificas y Técnicas (CONICET), CC 1260 Correo Central, \\ B7600WAG, Mar del Plata, Argentina \\ ${ }^{2}$ Department of Aquatic Ecology, Netherlands Institute of Ecology (NIOO-KNAW), \\ Droevendaalsesteeg 10, 6708, PB Wageningen, The Netherlands \\ ${ }^{3}$ Institute of Botany, Czech Academy of Sciences, Dukelská 135, 37982, Třeboň, Czech Republic \\ ${ }^{4}$ Conservation Ecology Group, Groningen Institute of Evolutionary Life Sciences, University of Groningen, \\ P.O. Box 11103, 9700, CC Groningen, The Netherlands
}

\begin{abstract}
Both bottom-up (e.g., nutrients) and top-down (e.g., herbivory) forces structure plant communities, but it remains unclear how they affect the relative importance of stochastic and deterministic processes in plant community assembly. Moreover, different-sized herbivores have been shown to have contrasting effects on community structure and function, but their effects on the processes governing community assembly (i.e., how they generate the impacts on structure) remain largely unknown. We evaluated the influence of bottom-up and top-down forces on the relative importance of deterministic and stochastic processes during plant community assembly. We used the data of a 7-yr factorial experiment manipulating nutrient availability (ambient and increased) and the presence of vertebrate herbivores ( $>1 \mathrm{~kg})$ of different body size in a floodplain grassland in The Netherlands. We used a null model that describes a community composition expected by chance (i.e., stochastic assembly) and compared the plant community composition in the different treatments with this null model (the larger the difference, the more deterministically assembled). Our results showed that herbivore exclusion promoted a more stochastic plant community assembly, whereas increased nutrients played a relatively minor role in determining the relative importance of stochasticity in community assembly. Large herbivores facilitated intermediate-sized mammal herbivores, resulting in synergistic effects of enhanced grazing pressure and a more deterministic and convergent plant community assembly. We conclude that herbivores can act as strong deterministic forces during community assembly in natural systems. Our results also reveal that although largeand intermediate-sized mammal herbivores often have contrasting effects on many community and ecosystem properties, they can also synergistically homogenize plant communities.
\end{abstract}

Key words: bottom-up effects; determinants of plant community diversity and structure; different-sized herbivores; null model; random and deterministic processes; top-down effects.

\section{INTRODUCTION}

The assembly of species into a local community on ecological timescales is influenced by deterministic and stochastic processes and dispersal (Vellend 2010). Deterministic processes are niche-related, include interspecific interactions and environmental forcing, and generally lead to convergent communities (little site-to-site variation in species composition) when environmental conditions are similar. Stochastic processes are neutralrelated (Hubbell 2001), include colonization/extinction dynamics and ecological drift and can lead to divergent communities (high site-to-site variation in species composition) among otherwise similar localities (Chase et al.

Manuscript received 2 October 2016; revised 20 December 2016; accepted 3 January 2017. Corresponding Editor: James T. Cronin.

${ }^{5}$ Present address: Department of Conservation Biology, Institute of Ecology and Evolution, University of Bern, Balzerstrasse 6, 3012, Bern, Switzerland.

${ }^{6}$ E-mail: jalberti@mdp.edu.ar.
2009, Chase and Myers 2011). The consensus is that both types of processes act simultaneously while their relative importance usually depends on the environmental context (Leibold and McPeek 2006, Adler et al. 2007, Yang et al. 2013). The challenge is to develop a framework that explicitly includes stochastic and deterministic processes and explores which factors influence the relative importance of each (Chase 2007, Chase and Myers 2011).

Analogously, there was also a long-lasting debate regarding whether top-down (i.e., herbivores and their predators) or bottom-up (i.e., nutrients, water, light) factors are the main structuring forces of plant communities, and it is now accepted that both forces simultaneously regulate the biomass and $\alpha$-diversity of primary producers (Hillebrand et al. 2007, Gruner et al. 2008). Top-down and bottom-up factors in isolation have been shown to affect the similarity in species composition and the relative importance of stochastic and deterministic processes during community assembly (nutrients [Chalcraft et al. 2008, Chase 2010], predation [Chase 
et al. 2009], granivory [Germain et al. 2013], physical stress [Chase 2007, Guo et al. 2014]). Indeed, community assembly is highly dependent on a multitude of bottom-up and top-down trophic influences (Caruso et al. 2011). However, the ways in which interactions between these processes regulate the outcome of determinism and stochasticity in community assembly are poorly understood and has not received much attention (but see Yang et al. 2013, Steiner 2014).

Evidence from natural communities shows that divergence in species composition (which might imply higher stochasticity) may increase with increasing productivity or nutrient availability (Chase and Leibold 2002, Chalcraft et al. 2004, Chase 2010). However, which processes lead to these patterns remains largely unanswered (Steiner 2014). Available evidence suggests that divergence (and stochasticity) increases with higher nutrient availability due to priority effects (Chase 2010, Kardol et al. 2013, Steiner 2014). This occurs likely because higher productivity generally leads to a higher rate of population growth, which facilitates the preemption or modification of niches before the arrival of late-arriving species (Fukami 2015). If the most abundant species differ between plots just by chance, higher nutrient availability allows them to more easily outcompete subordinate species, magnifying the original differences in abundance (see Chase 2010).

However, these bottom-up factors may be modified by top-down control. Particularly in terrestrial systems, it is well known that vertebrate herbivores influence local plant $\alpha$-diversity in a variety of direct and indirect ways (Olff and Ritchie 1998), depending on ecosystem productivity or nutrient availability: at low-productivity sites (or unfertilized treatments), the impact of herbivory on $\alpha$-diversity is negative, while it turns positive at highproductivity sites (or increased nutrient treatments; Bakker et al. 2006, Hillebrand et al. 2007), mainly by reducing competition for light (Borer et al. 2014). Furthermore, different-sized herbivores usually exhibit different feeding modes and preferences that differentially affect $\alpha$-diversity (i.e., intermediate-sized vertebrate herbivores usually show more unpredictable effects than large vertebrate herbivores; Bakker et al. 2006). In this context, Ritchie and Olff (1999) suggested that the combination of large- and intermediate-sized herbivores can have compensatory or additive effects on plant communities that likely depend on soil nutrients (additive herbivore effects on vegetation when soil nutrients are not limiting).

However, besides their effects on community composition and ecosystem functions, it is not clear if differentsized herbivores can also regulate the relative importance of niche-based vs. neutral-based processes behind those effects along productivity or nutrient availability gradients. So far, experimental results showed that consumers (herbivores, predators) in isolation can increase the relative importance of deterministic over stochastic community assembly, because consumers reduce the number of species that could live in those habitats (Chase et al. 2009), particularly by removing species without traits to deal with consumption (Germain et al. 2013).

Considering all the above, the main goal of this study was to determine whether top-down and bottom-up forces interact to regulate the balance between stochastic and deterministic plant community assembly. More specifically, we investigated to what degree intermediateand large-sized herbivores have a synergistic effect controlling the relative importance of stochastic and deterministic community assembly; and whether this effect of different-sized herbivores depends on soil nutrients. We expect an interaction between nutrient availability and grazing, in which (1) nutrients will promote a more stochastic plant community assembly that can be overruled by grazing (i.e., nutrient addition in the exclosures will result in a more stochastic community, but with herbivory this effect will be lost), (2) the combination of intermediate- and large-sized herbivores will lead to a more deterministic plant community assembly, and (3) particularly under increased nutrient availability due to increased grazing pressure.

\section{Methods \\ Study site}

In this study, we used data from a long-term experiment (Bakker et al. 2006, Veen et al. 2010, Smit and Ruifrok 2011) that was conducted in a 50-ha floodplain within the Junner Koeland area, a 100-ha nature reserve along the river Overijsselse Vecht in the northeast of The Netherlands $\left(52^{\circ} 32^{\prime} \mathrm{N}, 6^{\circ} 36^{\prime} \mathrm{E}\right)$. The aboveground annual net primary productivity is $489 \pm 19 \mathrm{~g} / \mathrm{m}^{2}$ (Bakker et al. 2006), which is intermediate in comparison with other natural grasslands (Borer et al. 2014). This area has been grazed by livestock for centuries and, during the course of this study, the site was grazed by cattle (1 heifer per 2.5 ha from April to October; Bakker and Olff 2003). Other larger $(>1 \mathrm{~kg})$ vertebrate herbivores that occur in the study site are European rabbit (Oryctolagus cuniculus), roe deer (Capreolus capreolus), and brown hare (Lepus europaeus; Smit and Ruifrok 2011), the latter two in very low densities. Vegetation in the grazed lawns is dominated by Agrostis capillaris and Festuca rubra (Smit and Ruifrok 2011). In addition, many (>40) subordinate species also occur, with annual rates of colonization and extinction above $40 \%$ (Bakker and Olff 2003).

\section{Experimental design}

To achieve our goals, we used data from a fertilization and herbivore exclusion experiment that was established in May 1994 in Junner Koeland and that lasted until 2001 ( $7 \mathrm{yr}$ ). Seven years is not enough to reach the climax of succession in temperate grasslands, where herbivore exclusion will likely lead to invasion by woody species and forests will establish (Olff et al. 1999). However, 
considering that our study is longer than others addressing related topics in similar systems (Germain et al. 2013, Yang et al. 2013), and the high rates of interannual colonization and extinction observed at our study site (Bakker and Olff 2003), we believe that the length of our study is consistent with our goals.

The experimental design consisted of five blocks with three $12 \times 12 \mathrm{~m}$ grazing treatments each: (1) unfenced areas accessible to all herbivores (hereafter "controls"), (2) areas fenced to exclude larger herbivores (i.e., cattle), but allowing access to smaller species (i.e., European rabbits; hereafter "large herbivore exclosures"), and (3) areas fenced to exclude all mammals $>1 \mathrm{~kg}$ (hereafter "full exclosures"), invertebrates and small rodents were not excluded. Large herbivore exclosures had two barbed wires at 0.5 and $1.0 \mathrm{~m}$ height. Full exclosures consisted of $1 \mathrm{~m}$ high chicken mesh. Within each replicate of each of the three grazing units, two $2 \times 2 \mathrm{~m}$ permanent plots were established following a randomized design. One of these was fertilized and the other was left unfertilized (Appendix S1: Fig. S1). Nutrients were administered twice per year from 1994 onward, once in mid-April and again in early May, at an amount of $15 \mathrm{~g} \mathrm{~N}$, $5 \mathrm{~g} \mathrm{P}$, and $10 \mathrm{~g} \mathrm{~K} \cdot \mathrm{m}^{-2} \cdot \mathrm{yr}^{-1}$. Nutrients were dissolved in $10 \mathrm{~L}$ water and evenly distributed over the plots. This nitrogen addition rate is above the atmospheric nitrogen deposition rates (Reay et al. 2008).

The vegetation composition in all plots was recorded annually for the $7 \mathrm{yr}$ (1995-2001) during peak biomass (late July-early August) by visually estimating cover following the decimal Londo scale (Londo 1976). Aerial cover was estimated visually per species by the same person in each year. Here we focus on the last year, but information regarding previous years can be found in Appendix S2. Total cover could exceed $100 \%$ if species vertically overlapped. To evaluate whether fertilization changed the grazing pressure in control plots (i.e., accessible to all herbivores), in the summer of the fourth year (July 1998), we measured grazing signs in leaves by putting a measuring stick $(50 \mathrm{~cm})$ horizontally on the vegetation. We inspected one leaf every $5 \mathrm{~cm}$ along the stick, and recorded whether it was grazed or not. We repeated this procedure five times, and thus, we sampled 50 leaves per plot.

Additionally, in order to compare our system to others, we also looked at the separate and combined impacts of herbivory and nutrients on vegetation height, photosynthetically active radiation (PAR) interception and $\alpha$-diversity. Our grassland showed responses to grazing and nutrients similar to many other grasslands worldwide (all the information regarding these and other analyses is available on the Appendix S2). Finally, we also measured rabbit dropping's rate to evaluate the potential facilitation from cattle to rabbits and substantiate the expected increased grazing pressure in control plots (Appendix S2).

\section{Data analysis}

We first explored the effects of grazing and nutrients on the variability in community composition, and then we explored if differences in variability between treatments were indicating differences in the relative importance of stochastic and deterministic processes in community assembly. Variability in community composition was evaluated using multivariate group dispersions (Anderson et al. 2006), based on the Bray-Curtis similarity index applied to fourth-root transformed data (to reduce the weight of the most abundant species on the index of similarity) and with 9,999 permutations. We restricted plot permutations within grazing treatments, and grazing treatments within blocks to account for the spatial dependence of the sampling units. We performed this analysis using the betadisper and permutest functions of the vegan package (Oksanen et al. 2015) for R. We did the analysis separately for the first and last year of the experiment, to evaluate whether the differences observed at the end of the experiment were already present at the beginning.

To be able to disentangle whether differences in variability were the product of differences in the relative importance of stochastic and deterministic processes in community assembly, we followed a null model approach that takes into account species abundances. Our approach is a slight modification (to consider species abundances) of the null model proposed by Chase et al. (2011), which in turn is a slight modification of the Raup-Crick index (Raup and Crick 1979). We included relative abundance of species because many studies showed that this carries useful information for understanding ecological processes (Hillebrand et al. 2008, Winfree et al. 2015). To achieve this, we followed a probability-based randomization (see Mori et al. [2015] for a discussion about abundance-based null models), in which we defined four constraints: (1) the number of species in a given plot was the same as the actual number of species observed in that plot, (2) the probability of each species to be sampled was the proportion of plots where this species was actually observed, (3) the total abundance (i.e., cover) in each randomly generated assembly was the same as the actual total abundance in that plot, and (4) the abundance probability of a given species was the actually observed proportional abundance of that species across all plots.

For a given pair of plots (30 plots in total: 2 nutrient treatments $\times 3$ grazing treatments $\times 5$ blocks; a pair could belong to different treatments), each plant community composition was probabilistically generated 9,999 times. For each iteration, the Bray-Curtis dissimilarity index between those two plots was calculated. Finally, the resulting metric was the proportion of iterations in which the calculated Bray-Curtis index was smaller or equal than the observed index (i.e., calculated from the experimental results). This index was then modified to range from -1 to 1 , by subtracting 0.5 and multiplying this difference by 2 (Chase et al. 2011, Stegen et al. 2013b). Hereafter, we will refer to this metric as $\mathrm{RC}_{\mathrm{ab}}$ (for abundance-based Raup-Crick). The resulting metric indicates whether a pair of plots is less similar (approaching 1), as similar (approaching 0), or more 
similar (approaching -1), than expected by chance. As this index becomes less similar to 0 (either positive or negative), the relative importance of deterministic processes increases (because the community assembly is less likely explained by chance). In other words, the higher the deviance from 0 (purely stochastic assembly), the more deterministic is the community assembly. Values approaching -1 (more similar than expected by chance) reflect processes that make replicates to converge (e.g., low site-to-site variability in species composition due to environmental filtering), while values approaching 1 (less similar than expected by chance) reflect processes that make experimental plots to diverge (e.g., higher siteto-site variability in species composition than expected by chance, due to spatial heterogeneity). The size of the species pool plays an important role in the calculation of this index, and following others (Chase 2010, Chase et al. 2011, Stegen et al. 2013a) we defined the species pool as the list of species found in the experimental plots throughout the experiment.

To evaluate the separate and interactive effects of herbivory and nutrients (fixed terms) on the relative importance of stochastic and deterministic processes, we developed mixed-effects models in which grazing units nested in blocks were considered as the random terms. We selected (from the dissimilarity matrix described in the preceding paragraph) the comparisons of each replicate of a treatment to all the other replicates of that treatment $(n=5$ replicates per treatment, therefore each plot had 4 comparisons; e.g., 1 vs. 2,1 vs. 3,1 vs. 4 , and 1 vs. 5). Our dependent variable was the mean $\mathrm{RC}_{\mathrm{ab}}$ on $\mathrm{a}$ plot level, and thus we calculated the mean $\mathrm{RC}_{\mathrm{ab}}$ between those four comparisons. This technique was used by Koerner et al. (2016) to eliminate issues with autocorrelation ( $n=5$ rather than $n=10)$. We used the nlme (Pinheiro et al. 2016) package for R to perform the linear mixed effects analyses. Visual inspection of residual plots did not reveal any obvious deviations from homoscedasticity or normality. The final model was selected using the likelihood ratio test (always consistent with the AIC criterion), first evaluating the significance of higher order interactions and then the main effects if interactions were nonsignificant (Zuur et al. 2009). There were no cases in which candidate models had similar likelihood ratios. For multiple comparisons, we used the function glht from the multcomp package (Hothorn et al. 2008).

\section{RESULTS}

The different treatments exhibited very similar spatial variability in species composition and abundance at the beginning of the experiment $\left(F_{5,24}=0.05, P=0.998\right.$; Fig. 1). However, at the end of the experiment, spatial variability was higher in full exclosures, followed by large herbivore exclosures (not statistically different from any of the two other treatments), while controls were very homogeneous $\left(F_{5,24}=4.47, P<0.001\right.$; Table 1, Fig. 1$)$. Furthermore, nutrient addition increased variability only within full exclosures. Despite the large differences in variability, there were relatively minor differences in the number of species found per treatment (i.e., all the species that appeared at least once among all replicates of a given treatment; ambient, control $=23$, large herbivore exclosure $=19$, full exclosure $=24$; fertilized, control $=23$, large herbivore exclosure $=18$, full exclosure $=19$ ) .

The balance between stochastic and deterministic plant community assembly after $7 \mathrm{yr}$ was strongly affected by grazing $\left(\chi^{2}=28.89\right.$, df $=2, P<0.001$; Fig. 2$)$, while nutrients played an insignificant role $\left(\chi^{2}=2.28, \mathrm{df}=1\right.$, $P=0.13$; Fig. 2), and these two factors did not interact $\left(\chi^{2}=1.50, \mathrm{df}=2, P=0.47\right.$; Fig. 2). Communities grazed by all herbivores (control plots) were highly convergent and more deterministically assembled than the other treatments. Full and large herbivore exclosures were marginally different, with the former being slightly more divergent than the latter.

Moreover, although in full exclosures there was a consistent shift from relatively high deterministic to a highly stochastic assembly during the first $4 \mathrm{yr}$ (and stabilized since then; Appendix S2: Fig. S5), the temporal pattern of species dominance in the different plots showed no clear trajectories (i.e., there was no consistent change in community composition; Appendix S2: Fig. S6).

Finally, grazers responded positively to the nutrient additions. In the control plots, nutrient addition doubled the grazing pressure from $18.4 \%(\mathrm{SE}=3.12)$ grazed leaves in ambient to $37.2 \%(\mathrm{SE}=3.89)$ in plots with added nutrients $\left(\chi^{2}=15.93\right.$, df $\left.=1, P<0.001\right)$. Particularly intermediate-sized herbivores (i.e., rabbits) preferred plots grazed by large herbivores (i.e., control plots) and fertilized over non-fertilized (Appendix S2: Results and Appendix S2: Fig. S4).

\section{Discussion}

In this study, we experimentally evaluated the influence of bottom-up (i.e., nutrients) and top-down (i.e., herbivory) forces on the relative importance of deterministic and stochastic processes during plant community assembly. Our results revealed that herbivores and nutrients affected the relative importance of stochastic and deterministic plant community assembly. Specifically, we found that when both large- and intermediate-sized herbivores were absent, the resulting plant community was more stochastically assembled than when they were present, while nutrients played a relatively minor role. Below we discuss how these results relate to our initial hypotheses and the literature.

\section{Bottom-up forces governing the relative importance of stochasticity and determinism in plant community assembly}

Whereas the impact of nutrients and herbivores on plant diversity is by now rather well-known, to our knowledge, there is little information regarding the joint 


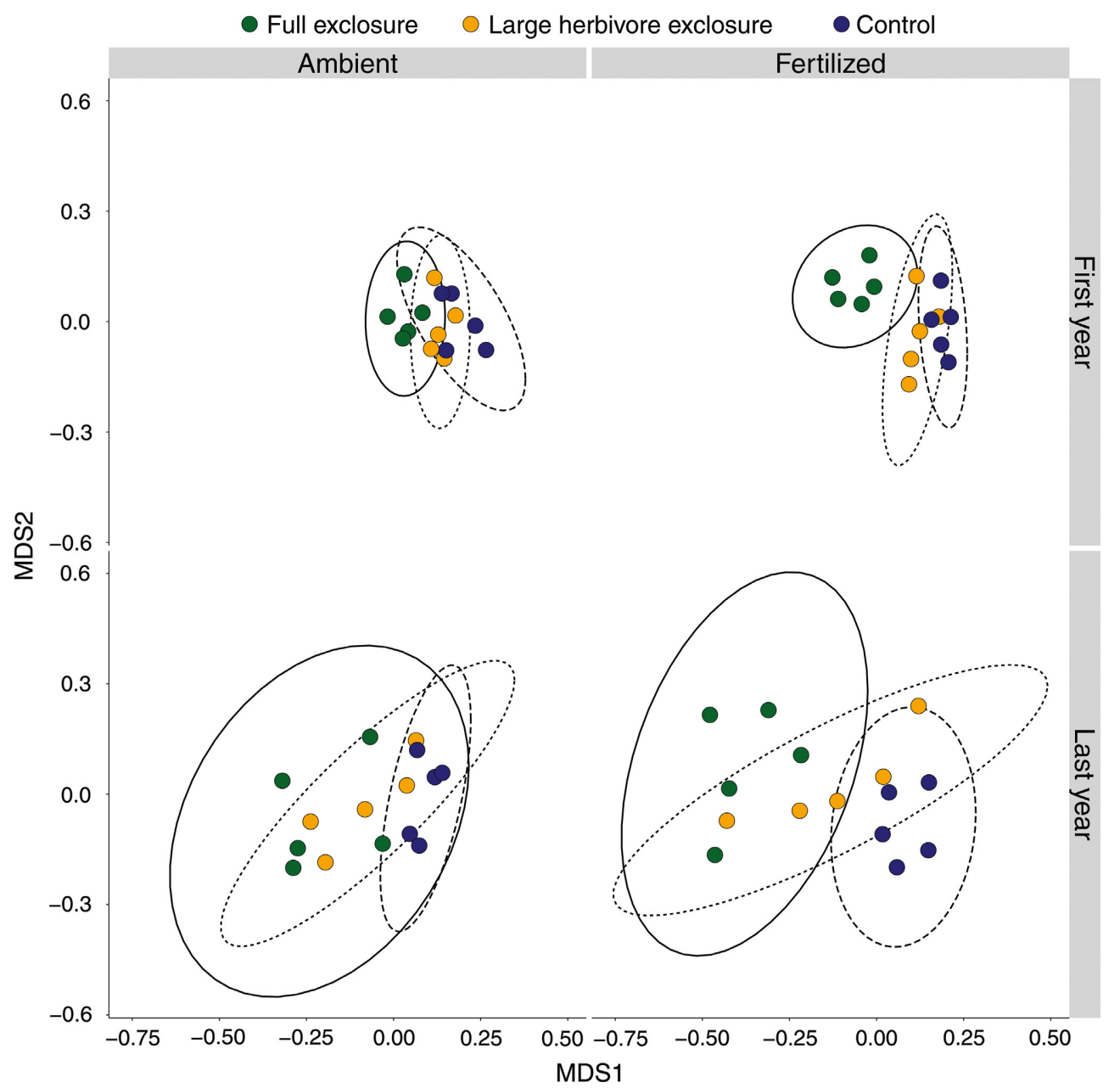

FIG. 1. Nonmetric multidimensional scaling (NMDS) ordination plot of community assemblages in two-dimensional space. Each point represents the species composition in a given replicate, and the distance between any two points represents the difference between those two community assemblages according to the Bray-Curtis dissimilarity index based on fourth-root-transformed data. Lines represent the confidence ellipse at the 0.95 level. The larger the ellipse of a given treatment, the greater variability of that treatment.

role of nutrients and different-sized herbivores regulating the processes behind plant community assembly. We hypothesized that nutrient addition will promote a more stochastic community assembly that can be overruled by grazing, but this hypothesis was not fully supported by our results. Instead we indeed found that herbivores overruled the nutrient effects (supported by the higher grazing pressure in control plots after fertilization), whereas in the full exclosures the plant community was more stochastically assembled than in the control plots, but the effect of fertilization was negligible. At least three alternative explanations emerge as to why nutrient addition did not lead to a more stochastic community assembly: (1) due to the intermediate productivity at our site, nutrient addition has no net effect on the divergence in species composition or on the balance between stochastic and deterministic community assembly (Chalcraft et al. 2008, Yang et al. 2013, Steiner 2014), (2) the lack of large differences in dominance between plots upon fertilization may account for the lack of an effect (Chase 2010, Kardol et al. 2013, Steiner 2014), and (3) the smaller effect of nutrients could also indicate that herbivores overruled the nutrient effects (supported by the higher grazing pressure in control plots after fertilization) and the effect of nutrients would only be visible in the full exclosures. However, this last possibility was only partially supported by our results; exclosures were, as expected, more stochastically assembled than control plots, but the effect of fertilization was negligible. The exclusion of large herbivores may be enough to induce a highly stochastic plant community assembly (supported in our case by $\mathrm{RC}_{\mathrm{ab}}$ values very close to 0 ), and thus, fertilization cannot cause a more stochastic plant community assembly. It could also be that large herbivores strongly reduce nitrogen mineralization $(\sim 40 \%$ lower in control plots; Bakker et al. 2004), leading to some sort of fertilization inside the exclosures, and thus decreasing the impact of fertilization. Either one of these explanations 
TABLE 1. Percent cover per treatment and block for the 12 species that reached a cover $\geq 20 \%$ at the end of the experiment.

\begin{tabular}{|c|c|c|c|c|c|c|c|c|c|c|c|c|c|}
\hline \multirow[b]{2}{*}{ Block } & \multirow[b]{2}{*}{ Nutrients } & \multicolumn{12}{|c|}{ Cover of each species $(\%)$} \\
\hline & & 1 & 2 & 3 & 4 & 5 & 6 & 7 & 8 & 9 & 10 & 11 & 12 \\
\hline \multicolumn{14}{|c|}{ Control } \\
\hline 1 & ambient & 50 & 60 & 10 & 1 & 1 & 4 & 0 & 0 & 0 & 0 & 0 & 0 \\
\hline 1 & increased & 60 & 60 & 20 & 1 & 1 & 4 & 0 & 0 & 0 & 0 & 0 & 0 \\
\hline 2 & ambient & 80 & 40 & 2 & 1 & 0 & 2 & 1 & 0 & 0 & 0 & 0 & 0 \\
\hline 2 & increased & 80 & 30 & 10 & 2 & 0 & 4 & 0 & 0 & 0 & 0 & 0 & 0 \\
\hline 3 & ambient & 60 & 60 & 0 & 0 & 0 & 10 & 0 & 0 & 0 & 0 & 0 & 0 \\
\hline 3 & increased & 70 & 50 & 0 & 0 & 0 & 2 & 0 & 0 & 0 & 0 & 0 & 1 \\
\hline 4 & ambient & 80 & 40 & 1 & 0 & 0 & 2 & 0 & 0 & 0 & 0 & 0 & 0 \\
\hline 4 & increased & 80 & 40 & 0 & 0 & 0 & 2 & 0 & 0 & 0 & 0 & 0 & 0 \\
\hline 5 & ambient & 80 & 30 & 1 & 2 & 0 & 2 & 0 & 0 & 0 & 0 & 0 & 0 \\
\hline 5 & increased & 70 & 50 & 10 & 1 & 0 & 2 & 0 & 0 & 0 & 0 & 0 & 0 \\
\hline \multicolumn{14}{|c|}{$\begin{array}{l}\text { Large } \\
\text { herbivore } \\
\text { exclosure }\end{array}$} \\
\hline 1 & ambient & 1 & 20 & 80 & 1 & 10 & 10 & 1 & 2 & 0 & 0 & 0 & 0 \\
\hline 1 & increased & 0 & 30 & 70 & 2 & 10 & 4 & 2 & 40 & 0 & 0 & 10 & 0 \\
\hline 2 & ambient & 80 & 10 & 4 & 0 & 10 & 10 & 0 & 4 & 0 & 0 & 0 & 0 \\
\hline 2 & increased & 40 & 30 & 40 & 0 & 0 & 20 & 1 & 0 & 0 & 0 & 0 & 0 \\
\hline 3 & ambient & 50 & 60 & 1 & 0 & 0 & 4 & 0 & 0 & 0 & 0 & 0 & 0 \\
\hline 3 & increased & 80 & 20 & 1 & 0 & 0 & 10 & 0 & 0 & 0 & 0 & 0 & 0 \\
\hline 4 & ambient & 80 & 40 & 1 & 0 & 0 & 4 & 0 & 0 & 0 & 0 & 0 & 0 \\
\hline 4 & increased & 90 & 30 & 0 & 0 & 0 & 1 & 0 & 0 & 0 & 0 & 0 & 0 \\
\hline 5 & ambient & 10 & 70 & 2 & 10 & 20 & 40 & 1 & 0 & 0 & 0 & 0 & 0 \\
\hline 5 & increased & 10 & 30 & 2 & 70 & 2 & 10 & 2 & 0 & 0 & 0 & 0 & 0 \\
\hline \multicolumn{14}{|c|}{$\begin{array}{l}\text { Full } \\
\text { exclosure }\end{array}$} \\
\hline 1 & ambient & 2 & 50 & 30 & 0 & 30 & 30 & 10 & 0 & 0 & 0 & 0 & 0 \\
\hline 1 & increased & 4 & 4 & 20 & 40 & 10 & 20 & 0 & 0 & 0 & 0 & 20 & 20 \\
\hline 2 & ambient & 1 & 2 & 90 & 0 & 0 & 20 & 1 & 1 & 0 & 0 & 0 & 0 \\
\hline 2 & increased & 0 & 0 & 90 & 0 & 0 & 2 & 40 & 0 & 0 & 0 & 0 & 0 \\
\hline 3 & ambient & 80 & 20 & 10 & 0 & 0 & 2 & 0 & 0 & 0 & 0 & 1 & 0 \\
\hline 3 & increased & 80 & 4 & 30 & 0 & 0 & 4 & 0 & 20 & 0 & 0 & 0 & 0 \\
\hline 4 & ambient & 30 & 10 & 60 & 0 & 0 & 1 & 1 & 0 & 0 & 0 & 0 & 0 \\
\hline 4 & increased & 20 & 4 & 80 & 0 & 0 & 1 & 0 & 0 & 0 & 0 & 0 & 0 \\
\hline 5 & ambient & 4 & 20 & 40 & 40 & 2 & 2 & 0 & 0 & 0 & 4 & 0 & 0 \\
\hline 5 & increased & 2 & 1 & 50 & 10 & 2 & 2 & 1 & 0 & 70 & 40 & 0 & 0 \\
\hline
\end{tabular}

Notes: Species are 1, Agrostis capillaris; 2, Festuca rubra; 3, Holcus lanatus; 4, Carex hirta; 5, Cirsium arvense; 6, Rumex acetosella; 7, Rumex crispus; 8, Urtica dioica; 9, Sambucus nigra; 10, Stachys palustris; 11, Arrhenatherum elatius; 12, Veronica chamaedrys. Boldface type highlights cover $\geq 20 \%$.

or a combination of them could be taking place at our study site.

\section{Top-down forces governing the relative importance of stochasticity and determinism in plant community assembly}

We confirm our second hypothesis in which we predicted that the joint absence of large- and intermediate-sized herbivores will lead to a more stochastic plant community assembly. However, we reject our third hypothesis (stronger impacts of herbivores when nutrients are added) because the results only showed minor differences following nutrient addition. Again, several mechanisms can explain these results. (1) Consumers (including herbivores and predators) usually lead to a more deterministic community assembly (Chase et al. 2009, Germain et al. 2013) because only a subset of the species tolerates the stress of being consumed (reducing variability between local communities). However, this mechanism does not seem to explain our results, given that there were only minor differences in the total number of plant species found between treatments. (2) When several plant species can become dominant light competitors, the end product of this competition is likely stochastic local extinction rather than deterministic (Segre et al. 2014). For example, the loss of short plant species as a group is deterministic, but which of those species disappear or which tall plant species becomes dominant from 


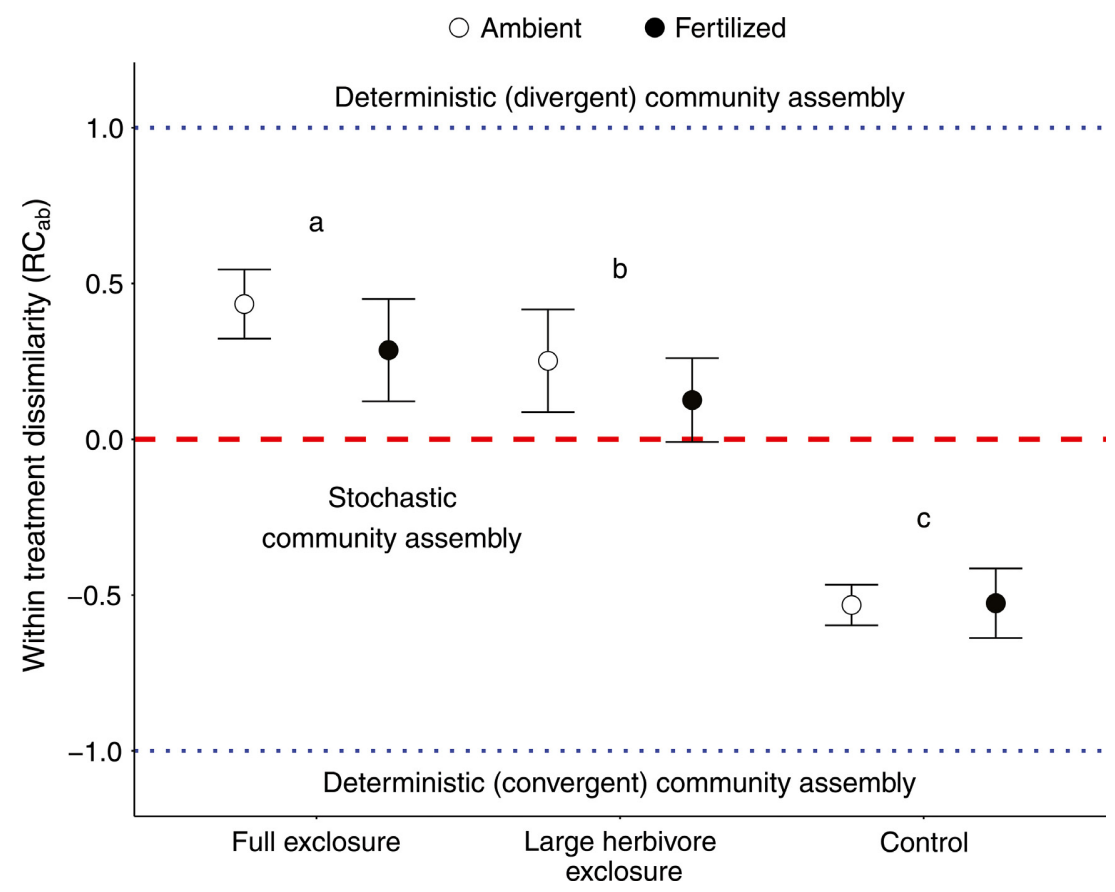

FIG. 2. Within-treatment dissimilarity (mean $\pm \mathrm{SE}$ ) according to a modified Raup-Crick dissimilarity metric $\left(\mathrm{RC}_{\mathrm{ab}}\right)$. This metric ranges from -1 to 1 , indicating whether a pair of plots are more dissimilar (approaching 1), as dissimilar (approaching 0), or less dissimilar (approaching -1), than expected by chance. The dashed horizontal gray line denotes a pure stochastic community assembly. Different letters denote significant differences between grazing treatments $(P<0.05$; note that the $P$ value for the comparison between full and large herbivore exclosures was 0.0575 ).

the group of dominant light competitors can be stochastic. Our case fits with this mechanism, given that we found the expected differences in plant species richness, vegetation height, and PAR interception between grazing treatments at the plot level (Appendix S2). Furthermore, only two plant species reached cover $>20 \%$ in a given control plot while seven plant species did it in full exclosures, and four of the five full exclosures did not share the same dominant plant species, while the same pair of plant species always dominated in control plots (Table 1). (3) Alternatively, it might be argued that adding treatments always produces alterations in the community composition, that vegetation takes some time to adapt to the new scenario, and thus, that changes in plant community are reflecting altered conditions rather than the effect of our treatments. This is inherent of the method of herbivore exclusion, from which most of the knowledge of large herbivore impacts on the vegetation diversity, composition and dynamics originates (see for instance, Milchunas and Lauenroth 1993, Bakker et al. 2006, 2016, Borer et al. 2014). Given that in our study we are analyzing spatial variability (and not temporal variability), there is no reason to suspect that the different replicates should respond differently (unless there were underlying differences in environmental conditions, which was not the case here [Bakker et al. 2004: Table 3]). Hence we are confident in our results, and we conclude that the most likely mechanism behind a more stochastic community assembly when herbivory is relaxed is the second (stochastic local extinction).

\section{Effects of different-sized herbivores}

We specifically hypothesized that the simultaneous exclusion of large- and intermediate-sized herbivores will strongly favor a more stochastic community assembly, or alternatively, that the combination of all herbivores will result in deterministic plant community assembly, which was confirmed by our results. Large- and intermediatemammal herbivores exhibit distinctive feeding modes and preferences (Semmartin and Oesterheld 2001, Kuijper et al. 2008), and have contrasting effects on plant $\alpha$-diversity (Milchunas and Lauenroth 1993, Bakker et al. 2006) and plant colonization dynamics (Bakker and Olff 2003). Whereas these distinct roles of large- and intermediate-sized herbivores are acknowledged, it remains unclear whether they have compensatory or additive effects on grassland vegetation (Ritchie and Olff 1999). In our study, large herbivore grazing was the most important driver of the more deterministic plant community assembly. At the end of the experiment, there were minor differences in the relative importance of stochasticity and determinism between both treatments without large herbivores (i.e., large herbivore and full exclosures). Nevertheless, intermediate-sized vertebrate herbivores played an important secondary role, because their absence (along with that of large herbivores) promoted a clear distinction between control plots (more convergent and deterministic plant community assembly) and full exclosures (more divergent and stochastically 
assembled). This was particularly due to a strong facilitative effect, where intermediate-sized mammal herbivores preferred to feed on plots grazed by large herbivores, imposing a stronger stress and thus promoting the more deterministic plant community assembly. Cattle reduced vegetation height, and short vegetation is preferred by rabbits, increasing overall grazing pressure on the control plots (Bakker et al. 2009). This facilitation from cattle to rabbits can also explain the intermediate pattern found in the large herbivore exclosures. After removing large grazers, while the vegetation is still short, rabbits can exert some control over the plants and retard the transition to the more stochastically assembled plant community. However, as vegetation grows and taller species become dominant, top-down control by rabbits decreases (as has also been observed in salt marshes with hares and geese: Kuijper et al. 2008) and eventually full exclosures and large-herbivore exclosures converge.

Although, in our system, large- and intermediate-sized vertebrate herbivores were mainly represented by cattle and rabbits, we argue that this can be seen as a simplified model system of the diversity of vertebrate grazers and their functional roles. Most natural grasslands were once grazed by a diversity of large herbivores, but many of the native large herbivores went extinct in the past or are seriously threatened in the present (Dirzo et al. 2014, Ripple et al. 2015). The rabbits are representative of a guild of small-medium-sized burrowing mammals, that includes prairie dogs, steppe pikas, and ground squirrels, which, despite having important impacts on grassland ecosystems, have not been frequently studied (see Davidson et al. 2010). Our study demonstrates the importance of interactions between large- and intermediate-sized herbivores, in this case, resulting in altered grazing pressure and synergistic effects on grassland vegetation, emphasizing the importance of taking into account the role of herbivore diversity in studying herbivore impacts on grassland vegetation.

\section{Conclusions}

Overall, one of our three predictions was confirmed. In our study, nutrients did not play an important role regulating the relative importance of stochastic and deterministic plant community assembly (prediction 1), the combination of large- and intermediate-sized herbivores promoted a more deterministic plant community assembly (prediction 2), but this was not strongly modulated by nutrient availability (prediction 3 ). This study shows that, at least in intermediately productive grasslands, top-down control can be more important than bottom-up forces in regulating the relative importance of stochastic and deterministic processes shaping plant community assembly. The enhanced grazing pressure in nutrient enriched plots (capable of overruling bottom-up effects at the plot level) that we found has been documented many times before in herbaceous systems. In salt marshes, for example, several studies showed that herbivores entirely suppress the otherwise large effect of fertilization (Bertness et al. 2008, Alberti et al. 2010). Grazing lawns are another common example where top-down forces overrule bottom-up effects; herbivores aggregate in nutrient hot-spots, keep vegetation short and return more nutrients fueling this positive feedback (Augustine et al. 2003, Cromsigt and Olff 2008). This study also reveals that the well-known effects of top-down forces overruling bottom-up effects on community and ecosystem properties might not regulate the relative importance of the processes behind community assembly. Finally, our results show that a higher diversity of consumers is more efficient in overruling nutrient effects, and that this synergistic effect does not necessarily depend on nutrient availability. Hence, our study suggests that an impoverishment in the diversity of vertebrate herbivore communities may result in a lesser capacity of top-down control on plant community assembly, leading to less predictable local communities.

\section{ACKNOWLEDGMENTS}

We thank J. P. Bakker for his insightful comments that greatly improved earlier versions of this manuscript. We also thank J. Stegen for kindly sharing his R code with the modification of the Raup-Crick index that takes into account species abundances. This project was supported by grants from CONICET and MINCyT to JA. ESB and HO were supported for this work by The Netherlands Organization for Scientific Research.

\section{Literature Cited}

Adler, P. B., J. HilleRisLambers, and J. M. Levine. 2007. A niche for neutrality. Ecology Letters 10:95-104.

Alberti, J., A. Méndez Casariego, P. Daleo, E. Fanjul, B. Silliman, M. Bertness, and O. Iribarne. 2010. Abiotic stress mediates top-down and bottom-up control in a Southwestern Atlantic salt marsh. Oecologia 163:181-191.

Anderson, M. J., K. E. Ellingsen, and B. H. McArdle. 2006. Multivariate dispersion as a measure of beta diversity. Ecology Letters 9:683-693.

Augustine, D. J., S. J. McNaughton, and D. A. Frank. 2003. Feedbacks between soil nutrients and large herbivores in a managed savanna ecosystem. Ecological Applications 13: $1325-1337$.

Bakker, E. S., J. L. Gill, C. N. Johnson, F. W. M. Vera, C. J. Sandom, G. P. Asner, and J.-C. Svenning. 2016. Combining paleo-data and modern exclosure experiments to assess the impact of megafauna extinctions on woody vegetation. Proceedings of the National Academy of Sciences of the United States of America 113:847-855.

Bakker, E. S., and H. Olff. 2003. Impact of different-sized herbivores on recruitment opportunities for subordinate herbs in grasslands. Journal of Vegetation Science 14:465-474.

Bakker, E. S., H. Olff, M. Boekhoff, J. M. Gleichman, and F. Berendse. 2004. Impact of herbivores on nitrogen cycling: contrasting effects of small and large species. Oecologia 138:91-101.

Bakker, E. S., H. Olff, and J. M. Gleichman. 2009. Contrasting effects of large herbivore grazing on smaller herbivores. Basic and Applied Ecology 10:141-150.

Bakker, E. S., M. E. Ritchie, H. Olff, D. G. Milchunas, and J. M. H. Knops. 2006. Herbivore impact on grassland plant 
diversity depends on habitat productivity and herbivore size. Ecology Letters 9:780-788.

Bertness, M. D., C. Crain, C. Holdredge, and N. Sala. 2008. Eutrophication and consumer control of New England salt marsh primary productivity. Conservation Biology 22: 131-139.

Borer, E. T., et al. 2014. Herbivores and nutrients control grassland plant diversity via light limitation. Nature 508:517-520.

Caruso, T., Y. Chan, D. C. Lacap, M. C. Y. Lau, C. P. McKay, and S. B. Pointing. 2011. Stochastic and deterministic processes interact in the assembly of desert microbial communities on a global scale. ISME Journal 5:1406-1413.

Chalcraft, D. R., S. B. Cox, C. Clark, E. E. Cleland, K. N. Suding, E. Weiher, and D. Pennington. 2008. Scale-dependent responses of plant biodiversity to nitrogen enrichment. Ecology 89:2165-2171.

Chalcraft, D. R., J. W. Williams, M. D. Smith, and M. R. Willig. 2004. Scale dependence in the species-richness-productivity relationship: the role of species turnover. Ecology 85:2701-2708.

Chase, J. M. 2007. Drought mediates the importance of stochastic community assembly. Proceedings of the National Academy of Sciences USA 104:17430-17434.

Chase, J. M. 2010. Stochastic community assembly causes higher biodiversity in more productive environments. Science 328:1388-1391.

Chase, J. M., E. G. Biro, W. A. Ryberg, and K. G. Smith. 2009. Predators temper the relative importance of stochastic processes in the assembly of prey metacommunities. Ecology Letters 12:1210-1218.

Chase, J. M., N. J. B. Kraft, K. G. Smith, M. Vellend, and B. D. Inouye. 2011. Using null models to disentangle variation in community dissimilarity from variation in $\alpha$-diversity. Ecosphere 2:1-11 art24.

Chase, J. M., and M. A. Leibold. 2002. Spatial scale dictates the productivity-biodiversity relationship. Nature 416:427-430.

Chase, J. M., and J. A. Myers. 2011. Disentangling the importance of ecological niches from stochastic processes across scales. Philosophical Transactions of the Royal Society B 366:2351-2363.

Cromsigt, J. P. G. M., and H. Olff. 2008. Dynamics of grazing lawn formation: an experimental test of the role of scaledependent processes. Oikos 117:1444-1452.

Davidson, A. D., et al. 2010. Rapid response of a grassland ecosystem to an experimental manipulation of a keystone rodent and domestic livestock. Ecology 91:3189-3200.

Dirzo, R., H. S. Young, M. Galetti, G. Ceballos, N. J. B. Isaac, and B. Collen. 2014. Defaunation in the Anthropocene. Science 345:401-406.

Fukami, T. 2015. Historical contingency in community assembly: integrating niches, species pools, and priority effects. Annual Review of Ecology, Evolution, and Systematics 46: $1-23$.

Germain, R. M., L. Johnson, S. Schneider, K. Cottenie, A. Gillis Elizabeth, and A. S. MacDougall. 2013. Spatial variability in plant predation determines the strength of stochastic community assembly. American Naturalist 182:169-179.

Gruner, D. S., et al. 2008. A cross-system synthesis of consumer and nutrient resource control on producer biomass. Ecology Letters 11:740-755.

Guo, H., K. Więski, Z. Lan, and S. C. Pennings. 2014. Relative influence of deterministic processes on structuring marsh plant communities varies across an abiotic gradient. Oikos 123:173-178.

Hillebrand, H., D. M. Bennett, and M. W. Cadotte. 2008. Consequences of dominance: a review of evenness effects on local and regional ecosystem processes. Ecology 89:1510-1520.
Hillebrand, H., et al. 2007. Consumer versus resource control of producer diversity depends on ecosystem type and producer community structure. Proceedings of the National Academy of Sciences USA 104:10904-10909.

Hothorn, T., F. Bretz, and P. Westfall. 2008. Simultaneous inference in general parametric models. Biometrical Journal 50:346-363.

Hubbell, S. P. 2001. The unified neutral theory of biodiversity and biogeography. Princeton University Press, Princeton, New Jersey, USA.

Kardol, P., L. Souza, and A. T. Classen. 2013. Resource availability mediates the importance of priority effects in plant community assembly and ecosystem function. Oikos 122:84-94.

Koerner, S. E., M. L. Avolio, K. J. La Pierre, K. R. Wilcox, M. D. Smith, and S. L. Collins. 2016. Nutrient additions cause divergence of tallgrass prairie plant communities resulting in loss of ecosystem stability. Journal of Ecology 104:1478-1487.

Kuijper, D. P. J., P. Beek, S. E. van Wieren, and J. P. Bakker. 2008. Time-scale effects in the interaction between a large and a small herbivore. Basic and Applied Ecology 9:126-134.

Leibold, M. A., and M. A. McPeek. 2006. Coexistence of the niche and neutral perspectives in community ecology. Ecology 87:1399-1410.

Londo, G. 1976. The decimal scale for releves of permanent quadrats. Vegetatio 33:61-64.

Milchunas, D. G., and W. K. Lauenroth. 1993. Quantitative effects of grazing on vegetation and soils over a global range of environments. Ecological Monographs 63:327-366.

Mori, A. S., S. Fujii, R. Kitagawa, and D. Koide. 2015. Null model approaches to evaluating the relative role of different assembly processes in shaping ecological communities. Oecologia 178:261-273.

Oksanen, J., F. G. Blanchet, R. Kindt, P. Legendre, P. R. Minchin, R. B. O'Hara, G. L. Simpson, P. Solymos, M. H. H. Stevens, and H. Wagner. 2015. vegan: community ecology package. R package version 2.3-0. http://CRAN.R-project. org/package $=$ vegan

Olff, H., and M. E. Ritchie. 1998. Effects of herbivores on grassland plant diversity. Trends in Ecology and Evolution 13:261-265.

Olff, H., F. W. M. Vera, J. Bokdam, E. S. Bakker, J. M. Gleichman, K. de Maeyer, and R. Smit. 1999. Shifting mosaics in grazed woodlands driven by the alternation of plant facilitation and competition. Plant Biology 1:127-137.

Pinheiro, J. C., D. Bates, S. DebRoy, S. Deepayan, and R Core Team. 2016. nlme: linear and nonlinear mixed effects models. $\mathrm{R}$ package version 3.1-128. https://CRAN.R-project.org/ package $=$ nlme

Raup, D. M., and R. E. Crick. 1979. Measurement of faunal similarity in paleontology. Journal of Paleontology 53: $1213-1227$

Reay, D. S., F. Dentener, P. Smith, J. Grace, and R. A. Feely. 2008. Global nitrogen deposition and carbon sinks. Nature Geoscience 1:430-437.

Ripple, W. J., et al. 2015. Collapse of the world's largest herbivores. Science Advances 1:e1400103.

Ritchie, M. E., and H. Olff. 1999. Herbivore diversity and plant dynamics: compensatory and additive effects. Pages 175-204 in H. Olff, V. K. Brown, and R. H. Drent, editors. Herbivores: between plants and predators. Blackwell Science, Oxford, UK.

Segre, H., R. Ron, N. De Malach, Z. Henkin, M. Mandel, and R. Kadmon. 2014. Competitive exclusion, beta diversity, and deterministic vs. stochastic drivers of community assembly. Ecology Letters 17:1400-1408.

Semmartin, M., and M. Oesterheld. 2001. Effects of grazing pattern and nitrogen availability on primary productivity. Oecologia 126:225-230. 
Smit, C., and J. L. Ruifrok. 2011. From protégé to nurse plant: establishment of thorny shrubs in grazed temperate woodlands. Journal of Vegetation Science 22:377-386.

Stegen, J. C., X. Lin, J. K. Fredrickson, X. Chen, D. W. Kennedy, C. J. Murray, M. L. Rockhold, and A. Konopka. 2013b. Quantifying community assembly processes and identifying features that impose them. ISME Journal 7: 2069-2079.

Stegen, J. C., et al. 2013a. Stochastic and deterministic drivers of spatial and temporal turnover in breeding bird communities. Global Ecology and Biogeography 22:202-212.

Steiner, C. F. 2014. Stochastic sequential dispersal and nutrient enrichment drive beta diversity in space and time. Ecology 95:2603-2612.

Veen, G. F. (Ciska), H. Olff, H. Duyts, and W. H. van der Putten. 2010. Vertebrate herbivores influence soil nematodes by modifying plant communities. Ecology 91 : $828-835$

Vellend, M. 2010. Conceptual synthesis in community ecology. Quarterly Review of Biology 85:183-206.

Winfree, R., J. W. Fox, N. M. Williams, J. R. Reilly, and D. P. Cariveau. 2015. Abundance of common species, not species richness, drives delivery of a real-world ecosystem service. Ecology Letters 18:626-635.

Yang, Z., H. Guo, J. Zhang, and G. Du. 2013. Stochastic and deterministic processes together determine alpine meadow plant community composition on the Tibetan Plateau. Oecologia 171:495-504.

Zuur, A., E. N. Ieno, N. Walker, A. A. Saveliev, and G. M. Smith. 2009. Mixed effects models and extensions in ecology with R. Springer Science \& Business Media, New York, New York, USA.

\section{SUPPORTING INFORMATION}

Additional supporting information may be found in the online version of this article at http://onlinelibrary.wiley.com/ doi/10.1002/ecy.1741/suppinfo 